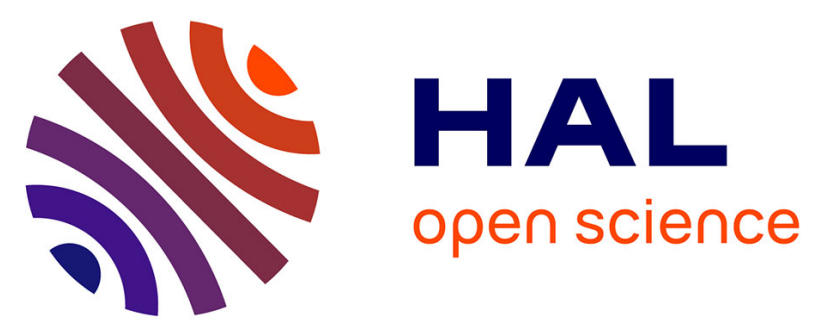

\title{
MindSpace: A Cognitive Behavioral Therapy Game for Treating Anxiety Disorders in Children
}

Barbara Göbl, Helmut Hlavacs, Jessica Hofer, Isabelle Müller, Hélen Müllner, Claudia Schubert, Halina Helene Spallek, Charlotte Rybka, Manuel Sprung

\section{- To cite this version:}

Barbara Göbl, Helmut Hlavacs, Jessica Hofer, Isabelle Müller, Hélen Müllner, et al.. MindSpace: A Cognitive Behavioral Therapy Game for Treating Anxiety Disorders in Children. 14th International Conference on Entertainment Computing (ICEC), Sep 2015, Trondheim, Norway. pp.463-468, 10.1007/978-3-319-24589-8_41. hal-01758422

\section{HAL Id: hal-01758422 \\ https://hal.inria.fr/hal-01758422}

Submitted on 4 Apr 2018

HAL is a multi-disciplinary open access archive for the deposit and dissemination of scientific research documents, whether they are published or not. The documents may come from teaching and research institutions in France or abroad, or from public or private research centers.
L'archive ouverte pluridisciplinaire HAL, est destinée au dépôt et à la diffusion de documents scientifiques de niveau recherche, publiés ou non, émanant des établissements d'enseignement et de recherche français ou étrangers, des laboratoires publics ou privés.

\section{(c)(1)}

Distributed under a Creative Commons Attribution| 4.0 International License 


\title{
MindSpace: A Cognitive Behavioral Therapy Game for Treating Anxiety Disorders in Children
}

\author{
Barbara Göbl ${ }^{1}$, Helmut Hlavacs ${ }^{1}$, Jessica Hofer ${ }^{2}$, Isabelle Müller ${ }^{2}$, Hélen \\ Müllner ${ }^{2}$, Claudia Schubert ${ }^{2}$, Halina Helene Spallek ${ }^{2}$, Charlotte Rybka ${ }^{2}$, and \\ Manuel Sprung ${ }^{2}$ \\ 1 University of Vienna, Research Group Entertainment Computing \\ ${ }^{2}$ University of Vienna, Faculty of Psychology
}

\begin{abstract}
We describe the design process and implementation of the serious game MindSpace. MindSpace provides a playful setting for treating children with a variety of social and specific anxiety disorders. An age-appropriate approach is explained, taking a closer look on cognitivebehavioral techniques, how they are implemented within a game setting and what special needs to take into account when designing for children in a therapeutic context.
\end{abstract}

\section{Introduction}

Anxiety disorders are among the leading psychological conditions in children and adolescents. Research undertaken in western countries reports prevalence figures of $10 \%$ and higher. They can potentially lead to anxiety disorders and depression in adult age, substance abuse or even suicide attempts [8]. Cognitive Behavioural Therapy (CBT) is an established treatment form to tackle these psychological conditions. Research suggests that CBT is not only as effective as pharmacotherapy but might also be superior in maintaining long-term beneficial effects [7].

However, several issues remain. Low availability of trained CBT therapists, as well as financial or time related problems [10], hinder access to therapeutical treatment. Given the high prevalence of anxiety disorders, this led to exploration of different alternatives to face-to-face treatment, such as group treatment, selfhelp delivered via telephone or computer supported treatment [11,12]. Many approaches to computerized CBT (CCBT) have been taken in recent years. Video games are a popular approach amongst children and were already successfully applied in several medical and psychological fields such as chemotherapy, chronic disease management or post-traumatic stress disorder [3,13]. By developing the serious game MindSpace, we aim to address the above mentioned issues and support therapists and children during treatment. 


\section{Related Work}

A variety of CCBT programs have been developed during recent years, with implementation being heavily dependant on resources, disorder and target group.

Regarding our young audience, projects such as BRAVE-ONLINE $[14,15]$ and Camp Cope-a-lot [9] come into focus. BRAVE-ONLINE mimicks sessions as they take place in face-to-face therapy and is accompanied by a therapist who is introduced via telephone and keeps up contact via mail. It aims to attract children with cartoon images and appropriate multimedia content. The Camp Cope-A-Lot CD (CCCD) targets children aged 7-12. Various media are used to provide affective education, teach relaxation techniques, give homework and go through exposure situations. To motivate the child, computer games are introduced as rewards. Instructions are included to allow non-trained supervisors to support the child. gNats [5] provides a video game approach to CBT, targeting 10-15 year old adolescents. It is intended to be used alongside face-to-face therapy and showcases the positive responses of both clinicians and adolescents to CCBT. Another example is Treasure Hunt, also fully implemented within a game setting and designed to support face-to-face therapy. The player is taken upon a ship and sent on a treasure hunt. Several tasks and mini-games include the principles of CBT. It is important to mention, that evaluation of programs who are exclusive to face-to-face treatment showed improvement in anxiety and depression, even without the help of trained therapists [11].

\section{Psychological Background}

CBT combines cognitive and behavioral aspects and is based on the idea of emotion, thoughts and behavior deeply affecting our well-being [1]. One of the main goals is to identify, control and adjust irrational behaviour and damaging thoughts. Some of the main aspects included in child CBT treatments are: assessment, psycho-education, coping techniques, exposure procedures and contingency management [6]. Assessment refers to both a first diagnosis as well as monitoring of the changes over time. An important part of assessment is to identify anxiety-provoking situations and put them into order. Psycho-Education relays important and helpful information about anxiety and its workings. Inaccurate views on anxiety and treatment are addressed to positively influence cognition and expectations. Furthermore, Coping Techniques include methods to help the child relax such as breathing techniques and muscle relaxation. Also, an important task of CBT is to raise awareness about maladaptive thoughts or self-talk and help adapt. Exposure Procedures refer to a gradual confrontation with the client's fears. Counterconditioning combines exposure with incompatible reactions such as relaxation. Extinction, on the other hand, confronts a client with anxiety triggering stimuli while using cognitive and behavioral techniques to control the situation and lower anxiety to a lower, manageable level. Lastly, Contingency Management puts emphasis on the consequences of a client's behavior, setting behaviour modification as a major goal. A traditional approach within cognitive-behavioral therapy is to work with rewards. 


\section{MindSpace}

To address the problem of child anxiety disorders, MindSpace ${ }^{3}$ was developed by an interdisciplinary team of computer scientist and psychologists. Concepts and therapy modules provided within the MindSpace game are loosely based on the "Modular Approach to Therapy for Children with Anxiety, Depression, Trauma, or Conduct Problems" [4] (MATCH). It is an evidence-based, specialized CBT manual giving detailed instructions on how to proceed throughout child CBT.

\subsection{Game Design}

MindSpace is a 2D, Flash based, jump \& run game, targeting children aged 712. Special focus was put on the skill level of our young target group as menus and buttons are mostly represented by graphics only, using simple, recognizable symbols and audio tutorials throughout the game. Game graphics and player characters are designed in a comic style, tailored to our young players.

There are a number of aspects that characterize MindSpace's unique approach to CBT. Firstly, while many programs are based on linked multimedia content, we provide an extensive game environment. Secondly, MindSpace is very flexible in adapting to the specific fears of children as it provides a large set of different anxieties and situations for exposure tasks. Lastly, MindSpace was designed to be self-explanatory, hence, while possible to use it as addition to face-to-face therapy, it is also intended to work with little to no assistance.

\subsection{Let's Play MindSpace}

Firstly, the player will go through an introductory phase, introducing the game and its context as well as gathering data about his or her anxieties. The Fear Ladder screen provides a list of pre-selected anxieties, represented with an icon and text, that can be sorted within the steps of the ladder. The game will henceforth focus on the top-most anxiety. In the next step, the Fear Thermometer is used to put situations into order according to how anxious the child is about them. Afterwards, the player will be taken to the Cockpit of his or her space craft, a fully graphical representation of the game's main menu. Five menu options are provided, each linking to another module of the game:

The Education Button starts the astronaut's training consisting of 3 different videos that teach the astronaut about anxiety and coping techniques. Clicking the window to Open Space and the Solar System, 10 planets are shown. Each planet represents a level which corresponds to a situation that has been sorted into the fear thermometer. Flags mark the planets he has successfully managed to play through, giving the player a sense of accomplishment. Levels lead through exposure situations but can also allow to collect up to 100 stars to trade in for playroom items. The Playroom represents a major part of the motivational system of the game. Here, players can use the collected stars

\footnotetext{
${ }^{3}$ http://barbarella.cs.univie.ac.at/mindspace/MindSpace.html
} 

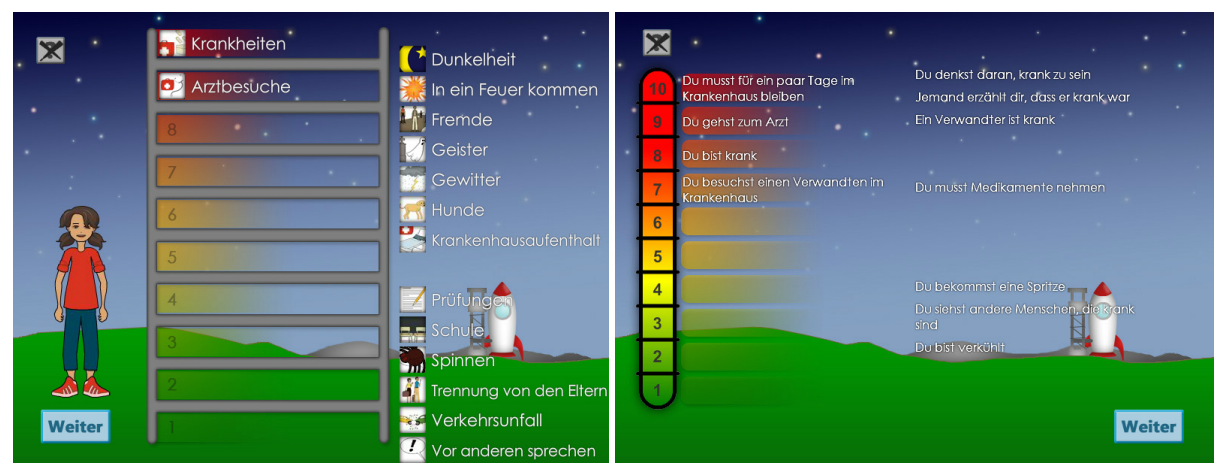

Fig. 1. Fear Ladder and Fear Thermometer

to exchange them for toys and items for their playroom. A further screen, the Statistics Display shows anxiety ratings for each individual level.

\subsection{In-Game Exposure and Monitoring}

The exposure situations are one of the core modules within the game. Each planet represents one of the situations sorted by the child using the fear thermometer. Exposure videos depict 15 different anxieties divided into 11 situations, each of them in different versions for both male and female players. This results in a total of 330 videos integrated in MindSpace, adding up to about 165 minutes of exposure material. Videos are composed using an age appropriate comic style $^{4}$. They depict situations in third person perspective, starring the character chosen by the player. Common anxieties such as darkness, public speaking, school, strangers or traffic accidents are covered. Choice of anxieties was based on statistical data about pre-valence of specific anxieties in children [2].

Before and after exposure, measurements are taken on a scale from 1-10 indicating how much fear the child feels at this moment. This allows for monitoring progress and to provide optional rehearsals of coping and relaxation when measures are high.

\subsection{In-Game Psycho-Education and Coping Techniques}

Psycho-education and coping techniques, representing astronaut training, are included using instructional videos. In Learning About Anxiety, the goal is to introduce the workings of anxiety, explain how it occurs naturally and motivate the child for exposure practice and further treatment. The second video, Cognitive STOP introduces the STOP method. The children are taught to replace worried thoughts with better, helpful thoughts to handle anxious situations. Lastly,

\footnotetext{
${ }^{4}$ http://www.pixton.com/
} 

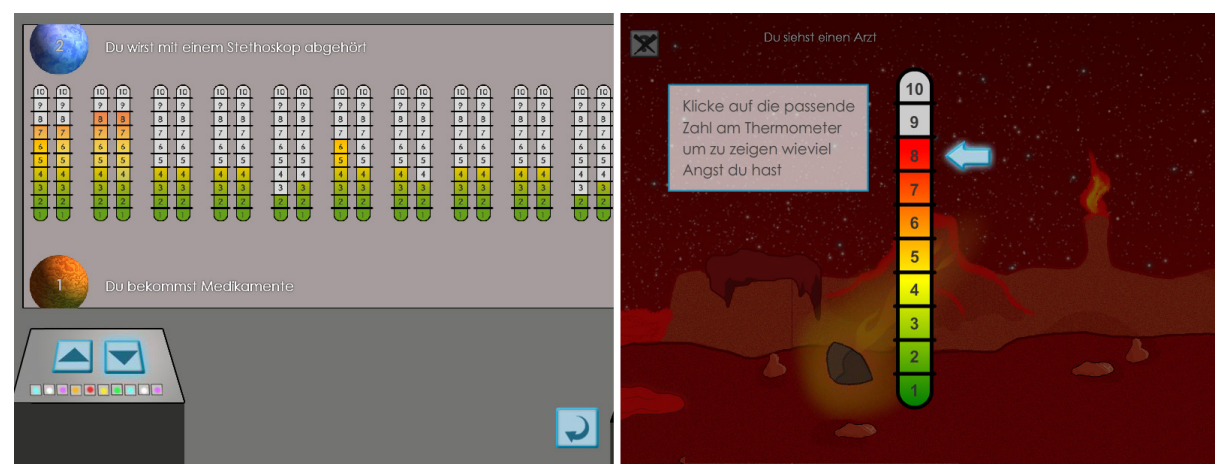

Fig. 2. The fear thermometer is a recurring motive used to display statistics and measure in-game anxiety

the Quick Calming video introduces relaxation techniques, helping the child to handle anxiety and relax when being fearful.

\section{Conclusion}

This paper provides a closer look on the CCBT game MindSpace and how psychological principles are implemented within a game setting. For one, we try to give insight into design considerations regarding our special target group. Both usability and game play need to be tailored to age and abilities. Also, therapy adherence is a important factor in psychological treatment that we tackle by including a reward system and additional motivational factors.

Experimental evaluation of MindSpace poses an important future task. While separate modules can be singled out for testing, such as efficacy of exposure tasks or the reward system, testing the overall effect of the game within clinical test groups is a long-term goal.

\section{References}

1. Kognitive verhaltenstherapie, http://www.gesundheitsinformation.de/kognitiveverhaltenstherapie.2136.de.html

2. Beesdo, K., Knappe, S., Pine, D.S.: Anxiety and anxiety disorders in children and adolescents: Developmental issues and implications for dsm-v. The Psychiatric clinics of North America 32(3), 483-524 (April 2009)

3. Ceranoglu, T.A.: Video games in psychotherapy. Review of General Psychology 14(2), 141-146 (2010)

4. Chorpita, B.F., Weisz, J.R.: MATCH-ADTC. PracticeWise, LLC (2009)

5. Coyle, D., McGlade, N., Doherty, G., O'Reilly, G.: Exploratory evaluations of a computer game supporting cognitive behavioural therapy for adolescents. In: Proceedings of the SIGCHI Conference on Human Factors in Computing Systems. pp. 2937-2946. CHI '11, ACM, New York, NY, USA (2011) 
6. Gosch, E.A., Flannery-Schroeder, E., Mauro, C.F., Compton, S.N.: Principles of Cognitive-Behavioral therapy for anxiety disorders in children. Journal of Cognitive Psychotherapy: An International Quarterly 20(3), 247-262 (2006)

7. Gould, R.A., Otto, M.W., Pollack, M.H., Yap, L.: Cognitive behavioral and pharmacological treatment of generalized anxiety disorder: A preliminary metaanalysis. Behavior Therapy 28(2), 285 - 305 (1997)

8. Kendall, P.C., Compton, S.N., Walkup, J.T., Birmaher, B., Albano, A.M., Sherrill, J., Ginsburg, G., Rynn, M., McCracken, J., Gosch, E., Keeton, C., Bergman, L., Sakolsky, D., Suveg, C., Iyengar, S., March, J., Piacentini, J.: Clinical characteristics of anxiety disordered youth. Journal of Anxiety Disorders 24(3), 360-365 (2010)

9. Khanna, M.S., Kendall, P.C.: Computer-assisted CBT for child anxiety: The coping cat cd-rom. Cognitive and Behavioral Practice 15(2), 159 - 165 (2008)

10. March, S., Spence, S.H., Donovan, C.L.: The efficacy of an internet-based cognitivebehavioral therapy intervention for child anxiety disorders. Journal of Pediatric Psychology 34(5), 474-487 (2009)

11. Proudfoot, J., Goldberg, D., Mann, A., Everitt, B., Marks, I., Gray, J.A.: Computerized, interactive, multimedia cognitive-beha-

vioural program for anxiety and depression in general practice. Psychological Medicine pp. 217-227 (2 2003)

12. Proudfoot, J., Ryden, C., Everitt, B., Shapiro, D.A., Goldberg, D., Mann, A., Tylee, A., Marks, I., Gray, J.A.: Clinical efficacy of computerised cognitive-behavioural therapy for anxiety and depression in primary care: randomised controlled trial. The British Journal of Psychiatry 185(1), 46-54 (2004)

13. Radkowski, R., Huck, W., Domik, G., Holtmann, M.: Serious games for the therapy of the posttraumatic stress disorder of children and adolescents. In: Shumaker, R. (ed.) Virtual and Mixed Reality - Systems and Applications, Lecture Notes in Computer Science, vol. 6774, pp. 44-53. Springer Berlin Heidelberg (2011)

14. Spence, S.H., Donovan, C.L., March, S., Gamble, A., Anderson, R., Prosser, S., Kercher, A., Kenardy, J.: Online cbt in the treatment of child and adolescent anxiety disorders: Issues in the development of brave-online and two case illustrations. Behavioural and Cognitive Psychotherapy 36, 411-430 (7 2008)

15. Spence, S.H., Donovan, C.L., March, S., Gamble, A., Anderson, R.E., Prosser, S., Kenardy, J.: A randomized controlled trial of online versus clinic-based cbt for adolescent anxiety. Journal of Consulting and Clinical Psychology 79(5), 629-642 (Oct 2011) 